\title{
Effects of adding nano-clay (montmorillonite) on performance of polyvinyl acetate (PVAc) and urea-formaldehyde (UF) adhesives in Carapa guianensis, a tropical species
}

\author{
Róger Moya ${ }^{\mathrm{a}, *}$, Ana Rodríguez-Zúñiga ${ }^{\mathrm{a}}$, José Vega-Baudrit ${ }^{\mathrm{b}}$, Vera Álvarez ${ }^{\mathrm{c}}$ \\ a Escuela de Ingeniería Forestal, Instituto Tecnológico de Costa Rica, Apartado, 159-7050 Cartago, Costa Rica \\ ${ }^{\mathrm{b}}$ Laboratório Nacional Nanotecnologia (LANOTEC), Centro Nacional de Alta Tecnologia-CENAT, San Jose, Costa Rica \\ c Grupo de Materiales Compuestos de Matriz Polimérica (CoMP) - Instituto de Investigaciones en Ciencia Y Tecnología de Materiales (INTEMA), \\ Mar del Plata, Argentina
}

\section{A R T I C L E I N F O}

Article history:

Accepted 9 February 2015

Available online 17 February 2015

Keywords:

Wood adhesives

Nanotechnology

Tropical species

Nano-clay

Thermal analysis

\begin{abstract}
A B S T R A C T
The aim of this study was to improve the bond strength resistance of polyvinyl acetate (PVAc) and ureaformaldehyde (UF) adhesives modified with nano-clay (montmorillonite) with a tropical species of wood known to exhibit adhesion related problems. These adhesives were evaluated with 1.0 and $1.5 \mathrm{wt} \%$ nanoclay concentrations with lap shear strength (SS), and the percentage of wood failure (PWF) in dry and wet conditions being evaluated. An additional aim of this study was to observe the presence of nano-clay within both adhesive types using Atomic Force Microscopy (AFM) and the Transmission Electron Microscopy (TEM). Color, viscosity and the thermostability of these adhesives with nano-clay were also evaluated. First, AFM and TEM studies showed adequate dispersion and impregnation of nano-clay. The viscosity of PVAc adhesive was not affected by the incorporation of nano-clay, whereas the UF adhesive was. With both PVAc and UF adhesives, the presence of nano-clay increased the $L^{*}$ and $b^{*}$ color parameters, especially when $1.5 \mathrm{wt} \%$ nano-clay was used. The incorporation of the nano-clay improved thermostability, as determined by thermogravimetric analysis (TGA). Finally, it was shown that the nano-clay incorporation improved SS and PWF. The highest values of SS were obtained when nano-clay was added at $1.5 \mathrm{wt} \%$ concentration in the PVAc adhesive under dry conditions. SS was not affected by nano-clay addition in the UF adhesive under dry conditions. However, under wet conditions, both 1.0 and $1.5 \mathrm{wt} \%$ loadings of nano-clay increased SS with both adhesive types. The addition of nano-clay in both proportions increased PWF by approximately $15 \%$ and between $20-30 \%$ in dry and wet conditions, respectively, for the PVAc adhesive. For the UF adhesive, PWF increased by approximately $10 \%$ under dry conditions and $25-50 \%$ in wet conditions.
\end{abstract}

(c) 2015 Elsevier Ltd. All rights reserved.

\section{Introduction}

Wood adhesives and wood products are important to the manufacturing of products for construction and for furniture production [1]. Adhesives are also used to produce wood composed products, such as plywood, fiberboard and oriented strand board (OSB) and also for wood re-use [2]. It is estimated that $70 \%$ of currently marketed products use adhesives [3]. Adhesives also improve the usefulness of wood, allowing the use of low-quality wood and of small-sized pieces so that wood waste can be more effectively used [3].

In addition, many adhesives are manufactured with synthetic products, which are easy to use, present a wide variety of

\footnotetext{
* Corresponding author.

E-mail addresses: rmoya@itcr.ac.cr (R. Moya), ana.rodriguez@itcr.ac.cr (A. Rodríguez-Zúñiga), jvegab@gmail.com (J. Vega-Baudrit), alvarezvera@fi.mdp.edu.ar (V. Álvarez).
}

applications, are low-cost and are designed using high technology [3]. In this regard, the development of nanotechnology, specifically nano-particles, has helped to produce a new generation of high performance adhesives [4]. Various nano-particles, layered silicates, aluminum oxide and nanocellulose among them, have been used to improve the performance of several wood adhesives [5].

Organo-clays derived from natural montmorillonite and modified with quaternary ammonium salt (dimethyl benzyl hydrogenated tallow ammonium) have been shown to improve the properties of polyvinyl acetate [2,7-9] and urea-formaldehyde adhesives [10-13]. However, the effect of nanoparticle incorporation on the performance of adhesives used with tropical wood is still unknown. While the behavior of adhesives with nanoparticles is relatively well understood in temperate countries, in regions of high temperature and high humidity, such as in tropical countries, it can create many problems [14]. Furthermore, tropical species have high specific gravity and high contraction coefficients 
which, together with the presence of naturally occurring resinous material, could influence joint integrity characteristics [15].

The purpose of this work was to study the performance in bond strength of the PVAc and UF adhesives modified with nano-clay (montmorillonite) with a tropical species (Carapa guianensis) having a high content of extractives and some adhesion problems $[16,17]$. It also showed the changes that occurred in the nano-clay due to modification with benzalkonium chloride and the change in color of the adhesive, thermal stability, entropy factor and activation energy in the decomposition kinetics of the PVAc and UF adhesives modified with nano-clay.

\section{Materials and methods}

\subsection{Materials}

The commercial clay Closite ${ }^{\circledR} \mathrm{Na}^{+}$, which is an unmodified montmorillonite supplied by Rocwood Clay based additives, was used as a nanofiller. According to the description of the supplier, the moisture content of the product ranges between 4-9\%, its density is $2.86 \mathrm{~g} \mathrm{~cm}^{-3}$ and the distribution of the size of the particles is as follows: $10 \%$ less than $2 \mu \mathrm{m}, 50 \%$ less than $6 \mu \mathrm{m}$ and $90 \%$ of the particles are less than $13 \mu \mathrm{m}$ in size. Benzalkonium chloride $\left(\mathrm{C}_{6} \mathrm{H}_{5} \mathrm{CH}_{2} \mathrm{~N}^{+}\left(\mathrm{CH}_{3}\right)_{2} \mathrm{RCl}^{-}\right)$was used to improve the miscibility of the layered silicates with the adhesive matrices (PVAc and UF) and the nanoclay, and it was chosen by several methods proposed by Ray and Okamoto [16].

Two types of wood adhesive were used. The first type was a waterbased polyvinyl acetate (PVAc), Resistol ${ }^{\mathrm{M} . R .} 850^{\circledR}$ trademark, produced by Henkel Capital S.A. (http://www.resistol.com.mx/es.html). The technical description of the product indicates that the resin is polyvinyl acetate and water, with $54.5-55.5 \%$ solid content and a viscosity of $1600-2200$ cPs. The second type of adhesive used was a water-based urea-formaldehyde (UF), CR-560 UF Resin trademark, produced by Central Chemistry Quibor SA (http://www.agroquibor.com). The technical description of the product indicates that the liquid resin is ureaformaldehyde (UF), with 64-65\% solids content and 650-900 cPs viscosity.

The species used for the adhesion tests was $C$. guianensis, which is a species traditionally used in Costa Rica for manufacturing doors and other wood-based products [17]. This species has presented problems with gluing [18] and is considered to demonstrate a behavior similar to the species Acer Saccharum or Acer nigrum, recommended by the ASTM D-905-08 standard for measuring the strength of the glue line [19]. This wood was obtained from three different sawn-wood marketing sites.

\subsection{Preparation of adhesives with nanoclays}

With both types of adhesive the nano-clay was added in three different concentrations: $0 \%$ (or control), $1 \%$ and 1.5\% (wt\%). According to studies carried out by Kaboorani and Riedl in temperate species [7], these proportions achieved the best performance. First, the commercial nano-clay was modified in order to improve chemical compatibility with both adhesive types. In order to improve affinity, a treatment of cation exchange with benzalkonium chloride was applied, based on the proposal of Ollier et al. $[20,21]$. The proposal was to treat the unmodified montmorillonite with the aqueous solution at $7 \%$ of benzalkonium chloride. For this, the nano-clay was mixed in a solution of ethanol-water (volume rate at $20: 80 \%$ ) at $60{ }^{\circ} \mathrm{C}$ for $1 \mathrm{~h}$ under stirring (solution A). Simultaneously a solution of $7 \%$ benzalkonium chloride (solution B) was prepared at room temperature, also stirring for $1 \mathrm{~h}$. After that time solution A was mixed with solution B. Both were mixed at a temperature of $60{ }^{\circ} \mathrm{C}$ with constant stirring for $12 \mathrm{~h}$. The mixture was then filtered until the chlorides test indicated no presence of chlorine, for which purpose a solution of saturated silver nitrate, as proposed by Ollier et al. [20], was used. Finally, the treated nano-clay was left to dry at $105{ }^{\circ} \mathrm{C}$, and once dry, it was pulverized in a mortar to achieve the finely ground nano-clay.

The various mixtures of adhesives modified with nano-clay were prepared as follows: (i) PVAc adhesive was stirred at $1600 \mathrm{rpm}$ for 15 min with the aid of four $45^{\circ}$-inclined d-blade impellers at room temperature, during which time the nano-clay was slowly added into the PVAc resin; and (ii) with UF adhesive, because it is a 3-component adhesive (resin, wheat flour, and catalyst of sulfates), the resin and flour were prepared and then mixed with the unmodified nano-clay. As in the previous case, the resin was stirred at $1600 \mathrm{rpm}$ for $15 \mathrm{~min}$ with the aid of an inclined blade $\left(45^{\circ}\right)$, while the nano-clay and flour were slowly added until dispersed in the resin.

\subsection{Adhesive characterization}

The extent to which the nano-clay was dispersed within the adhesive was assessed using Atomic Force Microscopy (AFM) and Transmission Electron Microscopy (TEM). With both techniques, an appropriate volume of adhesive with either $1 \%$ concentration of modified nano-clay (wt\%) or unmodified nano-clay at the same concentration was prepared. For TEM observations (trademark Jeol and JEM-2100 model), small samples of modified and unmodified clay were placed in the microscope, where a $100-\mathrm{kV}$ acceleration and $10,000 \times(B$ and $C$ ) and $300,000 \times(D)$ amplifications were used. Because AFM observations were performed in adhesive, they were carried out using a NanoScope $\mathrm{V}$, an atomic force microscope (model Asylum Research model MFP 3D) fitted with a Hybrid XYZ scanner. Atomic force microscope measurements were done under ambient air conditions in tapping mode. The sensitivity of the tip deviation and the scanner resolution was $0.3 \mathrm{~nm}$. The resolution was set to 250 lines by 256 pixels for all observations.

To measure viscosity, a 0.5 -liter sample of the two adhesives in the three concentrations of nano-clay was made and placed in the viscometer, Brokfield-11 + Pro LV. 2.4.4.

In the case of color assessment, a sample $3 \mathrm{~cm}$ wide, $10 \mathrm{~cm}$ long and approximately $2 \mathrm{~mm}$ thick was prepared with each adhesive. A neoprene rectangle $4 \mathrm{~mm}$ thick was formed on a glass and filled with the various adhesives prepared. When the solvent had completely separated (approximately $72 \mathrm{~h}$ later) the adhesive sample was removed and its color was measured. A Hunter Lab Scan XE Plus mini model spectrophotometer was used to obtain the $L^{*}, a^{*}$ and $b^{*}$ parameters. The measurement was set to within the visible range of $400-700 \mathrm{~nm}$ at intervals of $10 \mathrm{~nm}$ with a measuring aperture of $11 \mathrm{~mm}$. For the reflection reading, the observer component was set at an angle of $10^{\circ}$ to the sample's normal surface. According to HUNTERLAB [22], the CIE $L^{*}, a^{*}$ and $b^{* \prime}$ s color system estimates the color in three coordinates: $L^{*}$ for lightness that represents the position on the black-white axis ( $L=0$ for black, $L=100$ for white), $a^{*}$ for chroma value that defines the position on the red-green axis $(+100$ values for red, -100 values for green), and $b^{*}$ for chroma value that defines the position of the yellow-blue axis $(+100$ values for yellow, -100 values for blues). Three measurements were taken at each point to obtain the average values for the $L^{*}, a^{*}$ and $b^{*}$ coordinates. The color difference index $\Delta E^{*}$ of the adhesives, according to the ASTM D 2244 standard [23], was used to compare adhesive color parameters between adhesives with different concentrations of nanoclay. This index defines the wood color difference in magnitude between two adhesives using CIE $L^{*}, a^{*}$ and $b^{*}$ s color coordinates, according to Eq. 1 . This index was calculated using the average color values for all heartwood and sapwood samples from each adhesive.

$\Delta E^{*}=\sqrt{\left(\Delta L^{*}\right)^{2}+\left(\Delta a^{*}\right)^{2}+\left(\Delta b^{*}\right)^{2}}$

where $\Delta L^{*}=L^{* M}-L^{* P}, \Delta a^{*}=a^{* M}-a^{* P}, \Delta b^{*}=b^{* M}-b^{* P}, M=$ Average 
value for adhesive without nano-clay and $P=$ Average value for adhesive with nano-clay.

The thermal stability was analyzed for the two types of adhesives at the 3 concentrations of nano-clay. Measurements of TGA were carried out using 30-35 mg of each adhesive in each concentration, at a heating rate of $50{ }^{\circ} \mathrm{C} / \mathrm{min}$ in a nitrogen atmosphere reaching a temperature of $1000{ }^{\circ} \mathrm{C}$ in approximately $20 \mathrm{~min}$. A thermal gravimetric analysis model TGA 5000, Instrument $\mathrm{NBr}$ brand, was used. To analyze the information obtained, the reactions were identified with the aid of DTG. Two reactions were identified in the case of PVAc; only the second reaction was analyzed in UF, corresponding to polymer decomposition. The first corresponds to water elimination. For each reaction, the temperature and the mass remnant at the start of the reaction, at the maximum reaction point and at the end of the reaction, were identified. Next, the kinetics was calculated for each reaction (Eq. 1) by means of lineation (Eq. 2), according to Vyazovkin and Sbirrazzuoli [24], where the differential isoconversional method of Friedman is utilized.

$K=K_{0} * e^{\left(\frac{-E}{R T}\right)}$

$\ln \left(\frac{d \alpha}{d t}\right)=\ln K_{0}+\left(\frac{-E}{R T}\right)+n \ln (1-\alpha)$

where: $\alpha$ : degraded mass, $\mathrm{d} \alpha / \mathrm{d} t$ : percentage of the degraded sample in unit time, $K_{0}$ : entropy factor, $E$ : energy of activation, and $T$ : temperature.

\subsection{Bond strength}

Assessments of bond strength for the two types of resin with added nano-clay were evaluated by a compressive shear technique (SS), according to ASTM D-905-98 [19]. After preparing the two types of adhesives with nano-clay, the wood of $C$. guianensis was prepared and bonded. A total of 90 shear tests were carried out (30 samples per concentrations $\times 3$ concentrations). The wood was stabilized at a condition of $12 \%$ moisture for one week. The adhesive was applied in accordance with the manufacturer's specifications, which recommend an amount of $100 \mathrm{~g}^{-2}$ for both adhesives. After applying adhesive to the wood surface, the samples were pressed in a hydraulic machine at a pressure of $0.20 \mathrm{Nmm}^{-2}$ for $24 \mathrm{~h}$. Before pressurizing, bonded samples were conditioned to $20^{\circ} \mathrm{C}$ and $60 \%$ relative humidity for two weeks. Next, 30 samples were extracted and tested for each set of formulation. The SS was measured in dry and wet states under ambient air conditions. A Tinus Olsen hydraulic test machine with $10 \mathrm{kN}$ capacity was used for load application and the data were acquired by means of a computer. Wood failure and maximum load were recorded for each test. The block shear tests were carried out according to ASTM D905-98 [19]. The sizes of samples for "wet state" tests were the same as for "dry state" tests. For "wet state" tests, the samples were taken directly out of the water after being immersed for $24 \mathrm{~h}$. Before the tests, excess water was wiped from the samples. During the water immersion period, the temperature of the water was maintained at $20^{\circ} \mathrm{C}$. After each sample was tested in the compression test, the percentage of wood failure (PWF) was evaluated according to ASTM D-5266-13 standard [25].

\subsection{Analysis of the information}

Verification was made of compliance of the variables determined with the assumptions of normal distribution and variance homogeneity, as well as the presence of extreme data. Later, a variance analysis was performed to verify the effect of the adhesion of the nano-clay (three levels: $0 \%, 1 \%$ and $1.5 \%$ nanoclay) on viscosity, values of entropy factor, energy activation, decomposition function, and temperature and mass remnant in different reactions of the kinetics of decomposition. The Tukey test at a $99 \%$ confidence level was established to determine whether there was a statistically significant difference between the means.

\section{Results}

\subsection{Adhesive characterization}

\subsubsection{AFM and TEM observations}

With respect to the AFM analysis of the nano-clay modified adhesives, the adhesive surfaces with nano-clay were found to be irregular, with the presence of peaks. Fig. 1(a) and (b) shows AFM spectra for formulations having nano-clay concentrations of $1.0 \mathrm{wt} \%$ and $1.5 \mathrm{wt} \%$ for the UF adhesive. According to Fig. 1a, with the concentration of $1.5 \mathrm{wt} \%$, the number of peaks is higher than of a

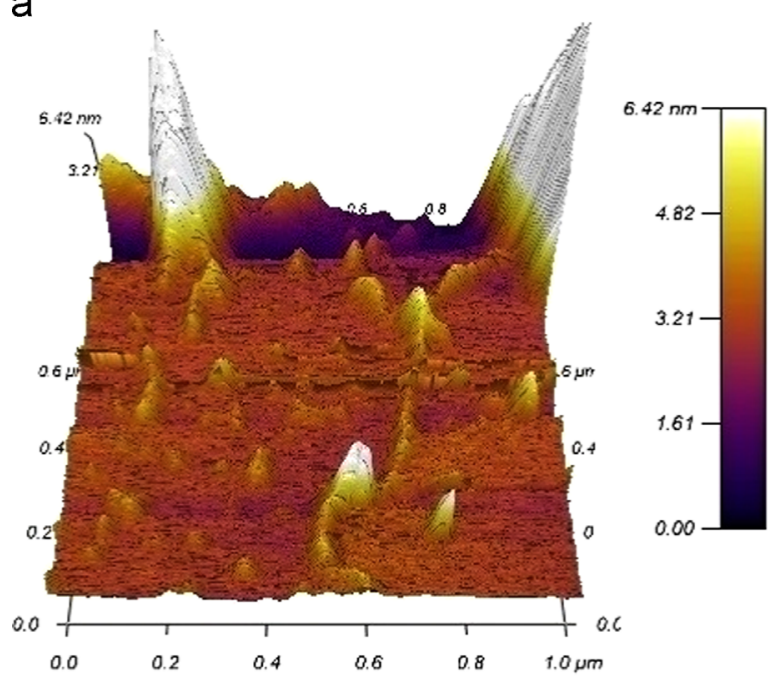

b

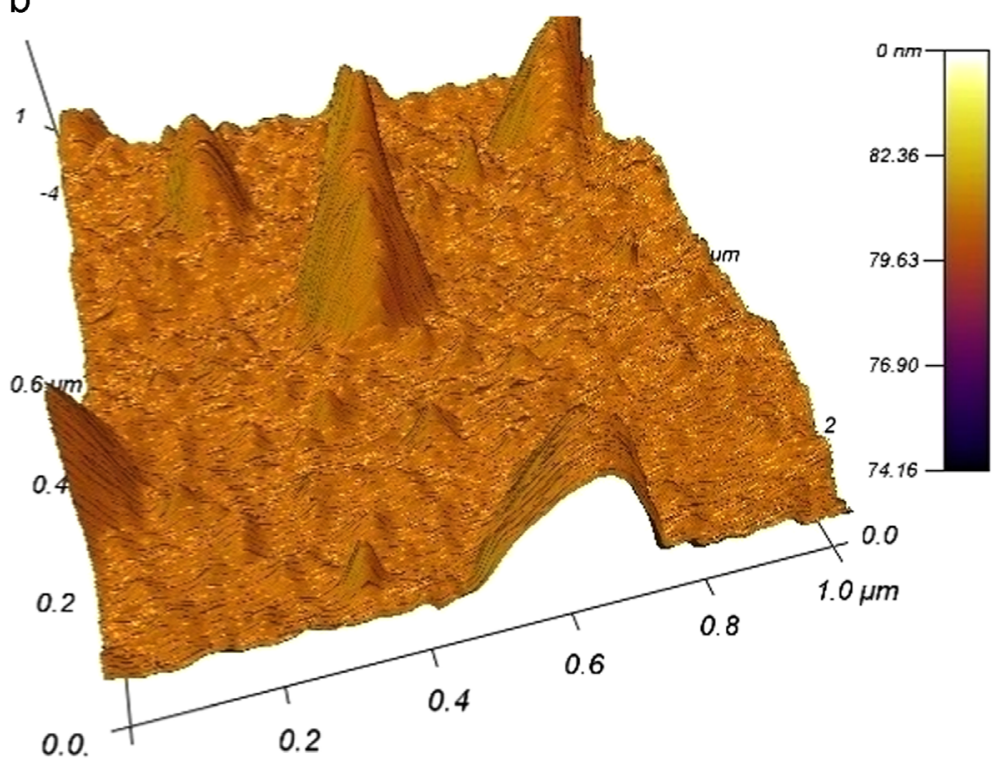

Fig. 1. Atomic force microscope-AFM spectra of nano-clay particles utilized in PVAc wood adhesive: (A) 1.5\% with nano-clay and (B) 1.0 nano-clay. 
those occurring in the UF adhesive with a concentration of $1 \%$ (Fig. 1b). The dispersion of peaks on the surface is uniform at both concentrations.

Fig. 2 shows TEM images obtained for the systems studied. First, it was observed that nano-clay particles appear short and tubular in some areas of the PVAc matrix (Fig. 2a-b). They are short and their diameter is almost $50 \mathrm{~nm}$ (Fig. 2a). In addition, it was observed that typical montmorillonite particles mixed in the PVAc matrix were of length approximately $1 \mu \mathrm{m}$ (Fig. 2c) and some montmorillonite particles had little separation between their clay layers (Fig. 2d).

\subsubsection{Viscosity and color}

Nano-clay statistically increases the viscosity of the adhesive in comparison with the adhesive without the nano-clay. In the case of the PVAc-type adhesive, no significant difference between the adhesive with $1.0 \mathrm{wt} \%$ and $1.5 \mathrm{wt} \%$ nano-clay contents was found regarding viscosity (Fig. 3a), whereas for the UF adhesive, the 3 types of nano-clay content were significantly different (Fig. 3b) and increased as a function of nano-clay content.

In relation to color of the various adhesives prepared (Table 1), luminosity ( $L^{*}$ parameter) was found to increase statistically in PVAc with the increment of the proportion of clay, while the $a^{*}$ parameter (redness) shows reduction only in the proportion $1.5 \mathrm{wt} \%$. Meanwhile, yellowness (the $b^{*}$ parameter) in the same type of adhesive statistically increases in the two proportions in relation to the adhesive without nano-clay. However, the greatest increment is observed in the $1 \%$ nano-clay samples (Table 1 ). Regarding the effects of the nano-clay in UF, it was found that both proportions of nano-clay affect the 3 color parameters, except for the $L^{*}$ parameter in the adhesive with $1 \%$ nano-clay (Table 2 ). Color change evaluation, determined by the $\Delta E^{*}$, shows that in PVAc adhesive the value is approximately 6 , while in UF the highest values, above 8.87 , are obtained when the proportion of nano-clay is $1.5 \mathrm{wt} \%$ (Table 1 ).

\subsubsection{Thermal stability of the adhesives}

The TGA spectrum of samples, unmodified or modified with the two concentrations of nano-clay (1.0 and $1.5 \mathrm{wt} \%$ ) and benzalkonium chloride, are presented in Fig. 4(a) and (b). The analysis of both PVAc and UF adhesives prepared with two concentrations of nano-clay (1.0 and $1.5 \mathrm{wt} \%$ ) showed two important inflexions in the mass loss of PVAc adhesive (Fig. 4a), whereas in the case of UF adhesive only one inflexion was observed (Fig. 4b). The first inflexion with the PAVc-adhesive occurs at approximately $315^{\circ} \mathrm{C}$ and the second at $425{ }^{\circ} \mathrm{C}$ (Fig. 4a), while with the UF adhesive the highest inflexion was observed at $260{ }^{\circ} \mathrm{C}$ (Fig. 4b). On the other hand, samples modified with nano-clay demonstrated different behavior to their un-modified counter parts (Fig. 4a-b) with benzalkonium chloride decomposition being much greater with adhesives containing nano-clay.

The analysis of the mass derivative as a function of the temperature (DTG) of the data obtained from the TGA experiments confirmed the various inflexions or reactions in the decomposition of the adhesives with different proportions of the nano-clay (Fig. 4(d) and (e)). DTG, however, first shows a stable mass loss as a function of temperature, augmenting the decomposition (starting point) until reaching a peak (highest point), then the decomposition drops until becoming stable once again (final point). With the PVAc, the first reaction of the adhesive without nano-clay occurs between $310^{\circ} \mathrm{C}$ and $327^{\circ} \mathrm{C}$, whereas in both types of PVAc with nano-clay the temperature range diminishes slightly to between $303{ }^{\circ} \mathrm{C}$ and $318{ }^{\circ} \mathrm{C}$. The second reaction, however, occurs within a similar range for all 3 types of nano-clay, between $325^{\circ} \mathrm{C}$ and
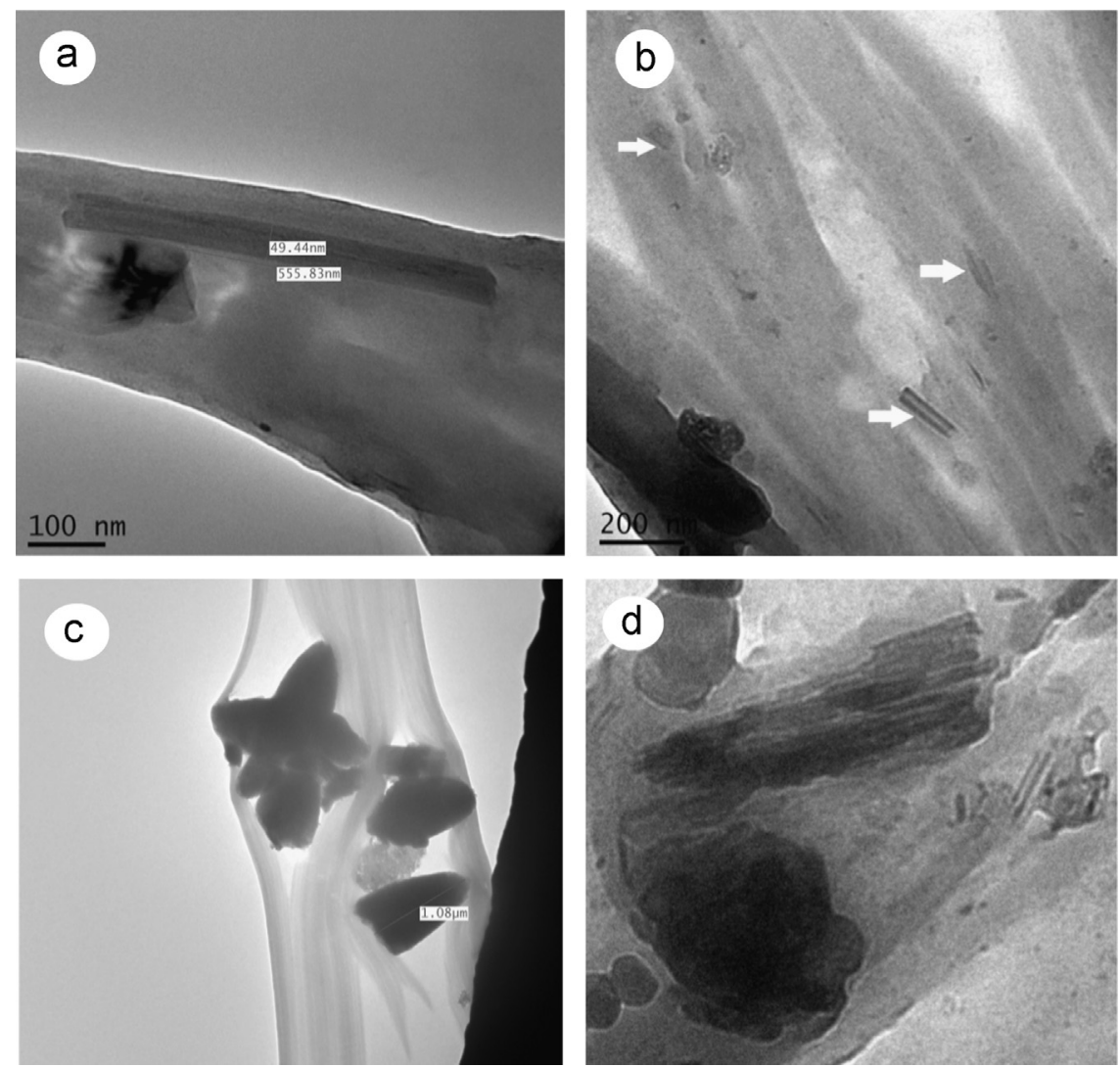

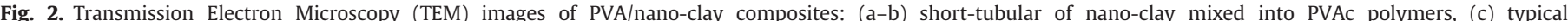
montmorillonite particles inside of two PVAc chain and (d) nano-clay in layers and particles mixed into PVAc adhesive. 
a

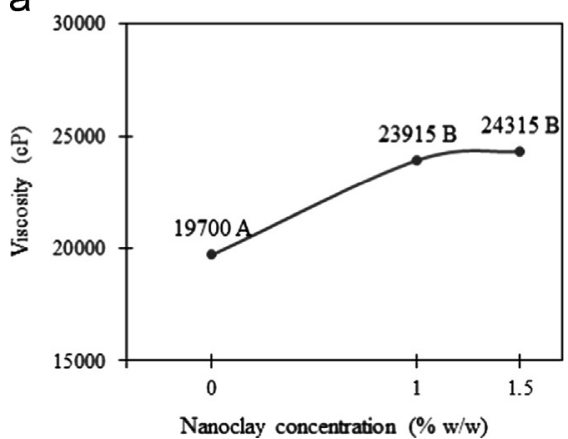

b

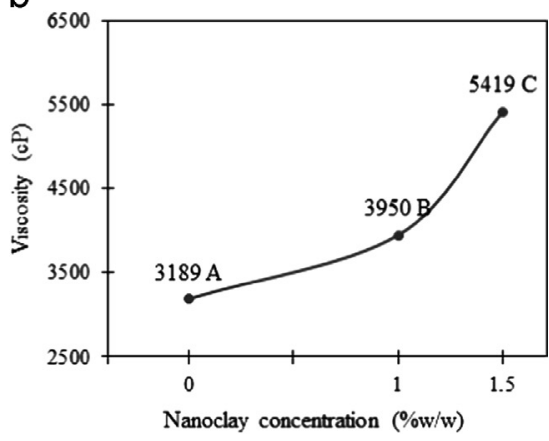

Fig. 3. Viscosity values of PVAc and UF wood adhesive, adding different concentrations (wt\%) of nano-clay.

Table 1

Adhesive color parameter of PVAc and UF adhesive with different nano-clay concentrations.

\begin{tabular}{|c|c|c|c|c|c|}
\hline Adhesive & Concentration (wt\%) & $L^{*}$ color parameter & $a^{*}$ color parameter & $b^{*}$ color parameter & $\Delta E^{*}$ \\
\hline \multirow[t]{3}{*}{ PVAC } & 0 & 47.67A & $-1.32 \mathrm{~A}$ & $-2.05 \mathrm{~A}$ & - \\
\hline & 1 & 49.61B & $-1.5 \mathrm{~A}$ & $0.06 \mathrm{~B}$ & 5.88 \\
\hline & 1.5 & $53.86 \mathrm{C}$ & $-2.52 \mathrm{~B}$ & $-1.50 \mathrm{C}$ & 6.33 \\
\hline \multirow[t]{3}{*}{ UF } & 0 & $39.89 A$ & $7.75 \mathrm{~A}$ & $14.46 \mathrm{~A}$ & - \\
\hline & 1 & $41.33 \mathrm{AB}$ & $9.21 \mathrm{~B}$ & 19.14B & 8.87 \\
\hline & 1.5 & $42.35 \mathrm{~B}$ & $8.93 B$ & 19.08B & 12.06 \\
\hline
\end{tabular}

Table 2

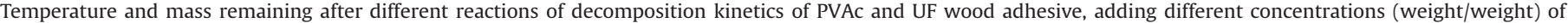
nano-clay.

\begin{tabular}{|c|c|c|c|c|c|c|c|c|c|c|c|c|c|c|}
\hline \multirow[t]{3}{*}{ Adhesive } & \multirow{3}{*}{$\begin{array}{l}\text { Nano-clay concentration } \\
\text { (wt\%) }\end{array}$} & \multicolumn{6}{|c|}{ Reaction 1} & \multicolumn{6}{|c|}{ Reaction 2} & \multirow{3}{*}{$\begin{array}{l}\text { Ash content } \\
(\%)\end{array}$} \\
\hline & & \multicolumn{2}{|c|}{ Initial point } & \multicolumn{2}{|c|}{ Maximum peak } & \multicolumn{2}{|c|}{ Final point } & \multicolumn{2}{|c|}{ Initial point } & \multicolumn{2}{|c|}{ Maximum peak } & \multicolumn{2}{|c|}{ Final point } & \\
\hline & & $\begin{array}{l}\text { Temp } \\
\left({ }^{\circ} \mathrm{C}\right)\end{array}$ & $\begin{array}{l}\text { MR } \\
(\%)\end{array}$ & $\begin{array}{l}\text { Temp } \\
\left({ }^{\circ} \mathrm{C}\right)\end{array}$ & $\begin{array}{l}\text { MR } \\
(\%)\end{array}$ & $\begin{array}{l}\text { Temp } \\
\left({ }^{\circ} \mathrm{C}\right)\end{array}$ & $\begin{array}{l}\text { MR } \\
(\%)\end{array}$ & $\begin{array}{l}\text { Temp } \\
\left({ }^{\circ} \mathrm{C}\right)\end{array}$ & $\begin{array}{l}\text { MR } \\
(\%)\end{array}$ & $\begin{array}{l}\text { Temp } \\
\left({ }^{\circ} \mathrm{C}\right)\end{array}$ & $\begin{array}{l}\text { MR } \\
(\%)\end{array}$ & $\begin{array}{l}\text { Temp } \\
\left({ }^{\circ} \mathrm{C}\right)\end{array}$ & $\begin{array}{l}\text { MR } \\
(\%)\end{array}$ & \\
\hline \multirow[t]{3}{*}{ PVAc } & 0 & $294^{\mathrm{A}}$ & $93.74^{\mathrm{A}}$ & $316^{\mathrm{A}}$ & $67.35^{\mathrm{A}}$ & $324^{\mathrm{A}}$ & $38.70^{\mathrm{A}}$ & $425^{\mathrm{A}}$ & $27.36^{\mathrm{A}}$ & $436^{\mathrm{A}}$ & $22.03^{\mathrm{A}}$ & $446^{\mathrm{A}}$ & $15.80^{\mathrm{A}}$ & $11.24^{\mathrm{A}}$ \\
\hline & 1.0 & $292^{\mathrm{A}}$ & $91.17^{\mathrm{A}}$ & $312^{\mathrm{A}}$ & $67.98^{\mathrm{A}}$ & $324^{\mathrm{A}}$ & $39.63^{A}$ & $425^{\mathrm{A}}$ & $26.04^{\mathrm{A}}$ & $433^{\mathrm{A}}$ & $21.60^{\mathrm{A}}$ & $448^{\mathrm{A}}$ & $13.86^{\mathrm{A}}$ & $10.01^{\mathrm{A}}$ \\
\hline & 1.5 & $303^{A}$ & $87.78^{\mathrm{B}}$ & $312^{\mathrm{A}}$ & $68.67^{\mathrm{A}}$ & $319^{\mathrm{B}}$ & $42.00^{\mathrm{B}}$ & $418^{\mathrm{A}}$ & $27.54^{\mathrm{A}}$ & $434^{\mathrm{A}}$ & $21.39^{\mathrm{A}}$ & $447^{\mathrm{A}}$ & $14.81^{\mathrm{A}}$ & $12.01^{\mathrm{A}}$ \\
\hline \multirow[t]{3}{*}{ UF } & 0 & - & - & - & - & - & - & $237^{\mathrm{A}}$ & $81.34^{\mathrm{A}}$ & $248^{\mathrm{A}}$ & $66.83^{\mathrm{A}}$ & $246^{\mathrm{A}}$ & $53.80^{\mathrm{A}}$ & $13.30^{\mathrm{A}}$ \\
\hline & 1.0 & - & - & - & - & - & - & $244^{\mathrm{B}}$ & $80.87^{\mathrm{A}}$ & $254^{\mathrm{B}}$ & $69.70^{\mathrm{B}}$ & $264^{\mathrm{B}}$ & $57.30^{\mathrm{B}}$ & $14.33^{\mathrm{A}}$ \\
\hline & 1.5 & - & - & - & - & - & - & $243^{B}$ & $80.93^{\mathrm{A}}$ & $254^{\mathrm{B}}$ & $69.87^{\mathrm{B}}$ & $264^{\mathrm{B}}$ & $58.23^{\mathrm{B}}$ & $15.00^{\mathrm{A}}$ \\
\hline
\end{tabular}

Temp: temperature, MR: mass remnant.

$345{ }^{\circ} \mathrm{C}$ (Fig. 4d). The adhesives prepared with UF show similarity between the adhesives with and without nano-clay (Fig. 4e). Similarly, the 2 proportions of nano-clay (1.0 and 1.5\%) show important mass loss under $100{ }^{\circ} \mathrm{C}$, although the greatest loss is observed between $200{ }^{\circ} \mathrm{C}$ and $400{ }^{\circ} \mathrm{C}$ (Fig. 4e).

Temperatures and mass remnants involved in each reaction of the different adhesives are detailed in Table 2. No significant difference was observed in the initial, final and maximum peak temperatures and mass remnant in the first and second reactions of the PVAc adhesive, between $1 \mathrm{wt} \%$ of nano-clay and the adhesive without nano-clay. The $1.5 \mathrm{wt} \%$ nano-clay adhesive, however, shows differences in the initial temperature of the mass remnant in the initial and final points and the final temperature of the first reaction (Table 2). Nano-clay adhesion to the UF adhesive, regardless of the percentage loading, produces a significant alteration in the temperature and mass remnant of the analyzed reaction 2 , with the exception of the mass remnant at the start of the reaction, where no difference is observed in the proportions and the adhesive is without nano-clay. No significant differences were found in the adhesives with $1.0 \mathrm{wt} \%$ and $1.5 \mathrm{wt} \%$ between the various parameters evaluated (Table 2 ).
Another aspect evaluated regarding TGA behavior was the amount of ash remnant. Neither of the two adhesive types showed a difference between the adhesives without nano-clay and the adhesives with nano-clay in either of the concentrations studied (Table 2).

Combustion kinetics of the different types of adhesives with the distinct nano-clay proportions was determined based on the first order of the reactions present during the decomposition of the adhesives (Table 3). The activation energy of the adhesive without the nano-clay is statistically lower than the energy that occurs in the adhesive with $1.0 \mathrm{wt} \%$ and $1.5 \mathrm{wt} \%$ nano-clay, and increased as a function of nano-clay content (Table 3). Likewise, differences were found between the entropy factor and the function of composition of the combustion kinetics in the adhesive reactions. In the PVAc, the adhesive entropy factor was statistically superior to that of the adhesive with nano-clay in the first and second reactions and the degree of decomposition function is again statistically higher than for nano-clay adhesives in the two reactions. While in the UF resin, $1 \mathrm{wt} \%$ nano-clay added to the adhesive presents no significant difference from the adhesive without nano-clay, whereas adding $1.5 \mathrm{wt} \%$ produces a significant 

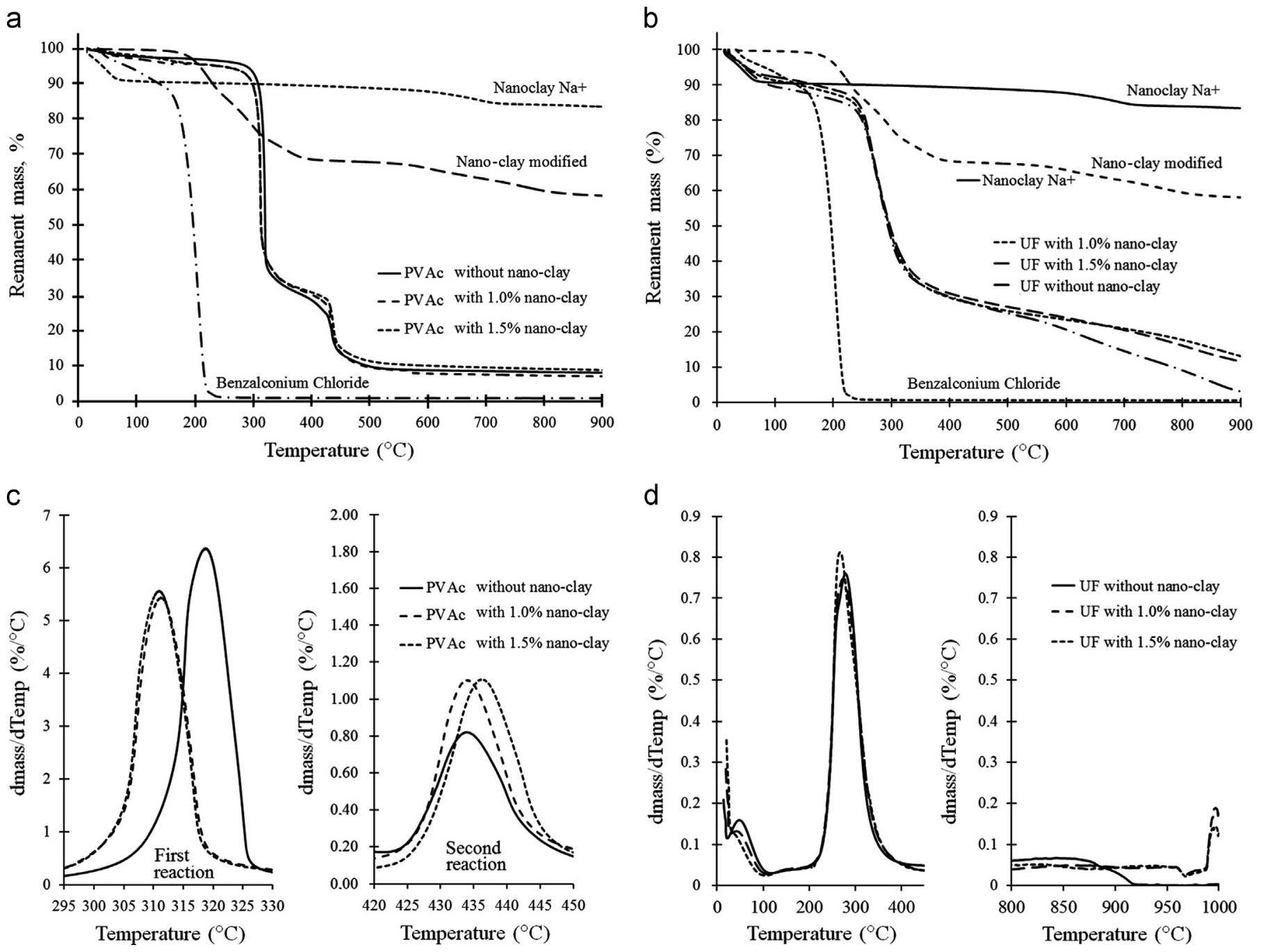

Fig. 4. TGA (a, b) and DTG of different reaction (c, d) curves of PVAc and UF wood adhesive, adding different concentrations of nano-clay.

Table 3

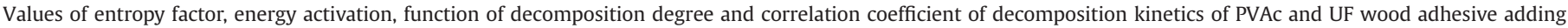
different concentrations (weight/ weight) of nano-clay.

\begin{tabular}{|c|c|c|c|c|c|c|}
\hline Adhesive & Reaction & $\begin{array}{l}\text { Nano-clay concentration } \\
\text { (wt\%) }\end{array}$ & $\begin{array}{l}\text { Entropy factor } \\
\left(K_{0} \text { in } \mathrm{s}^{-1}\right)\end{array}$ & $\begin{array}{l}\text { Energy activation } \\
\left(E \text { in } \mathrm{kJ} \mathrm{mol}^{-1}\right)\end{array}$ & $\begin{array}{l}\text { Function of decomposition degree } \\
(n)\end{array}$ & $\begin{array}{l}\text { Correlation coefficient } \\
(R)\end{array}$ \\
\hline \multirow[t]{6}{*}{ PVAC } & \multirow[t]{3}{*}{ First } & 0 & ${ }^{A} 3.87 \times 10^{25}$ & A 3.8 & ${ }^{\mathrm{A}} 1.95$ & 0.72 \\
\hline & & 1.0 & ${ }^{B} 7.04 \times 10^{2}$ & ${ }^{\mathrm{B}} 8.1$ & ${ }^{\mathrm{B}} 0.45$ & 0.58 \\
\hline & & 1.5 & ${ }^{c} 2.03 \times 10^{1}$ & ${ }^{c} 13.7$ & ${ }^{\mathrm{B}} 0.63$ & 0.70 \\
\hline & \multirow[t]{6}{*}{ Second } & 0 & $\mathrm{~A}_{3.58 \times 10^{21}}$ & ${ }^{\mathrm{A}} 242.9$ & ${ }^{\mathrm{A}} 18.61$ & 0.83 \\
\hline & & 1.0 & ${ }^{\mathrm{B}} 6.88 \times 10^{0}$ & В 259.9 & ${ }^{\mathrm{B}} 9.49$ & 0.91 \\
\hline & & 1.5 & ${ }^{C} 2.38 \times 10^{12}$ & ${ }^{\mathrm{c}} 281.2$ & ${ }^{c} 13.07$ & 0.88 \\
\hline \multirow[t]{3}{*}{ UF } & & 0 & ${ }^{A} 7.02 \times 10^{28}$ & ${ }^{\mathrm{A}} 240.6$ & ${ }^{A} 8.55$ & 0.98 \\
\hline & & 1.0 & ${ }^{\mathrm{A}} 2.11 \times 10^{27}$ & ${ }^{\mathrm{B}} 268.7$ & A8 8.56 & 0.98 \\
\hline & & 1.5 & ${ }^{\mathrm{B}} 2.03 \times 10^{23}$ & ${ }^{c_{2}} 287.6$ & ${ }^{\mathrm{B}} 6.83$ & 0.98 \\
\hline
\end{tabular}

difference from the adhesive without nano-clay and with $1.0 \mathrm{wt} \%$ of nano-clay (Table 3).

\subsubsection{Bond strength}

The results showed that adding nano-clay to PVA improves the shear strength of glue line (SS) in dry and wet conditions (Fig. 5a). However, the best results were obtained when nano-clay is added at $1.5 \mathrm{wt} \%$ and under wet conditions in both nano-clay proportions (Fig. 5b). In the UF type resin, although the nano-clay in both proportions increased SS, this increase was not significant in the dry condition (Fig. 5c). Meanwhile, the best result in SS of the nano-clays was obtained under wet conditions because the highest statistical SS was observed with 1.0 or $1.5 \mathrm{wt} \%$ nano-clay content in the adhesive (Fig. 5d).

Although the SS was not as effective, an evaluation of PWF found that the addition of nano-clay in the two proportions decreased PWF (Table 4). Under dry conditions, in the PVAc adhesive, the wood failure rate decreased by $15 \%$, while under wet conditions, the percentage reduction was greater, between $20-30 \%$. In the UF adhesive, the failure rate also decreased by $10 \%$ under dry conditions, $25 \%$ in the proportion of $1.0 \%$ and $50 \%$ under 
a

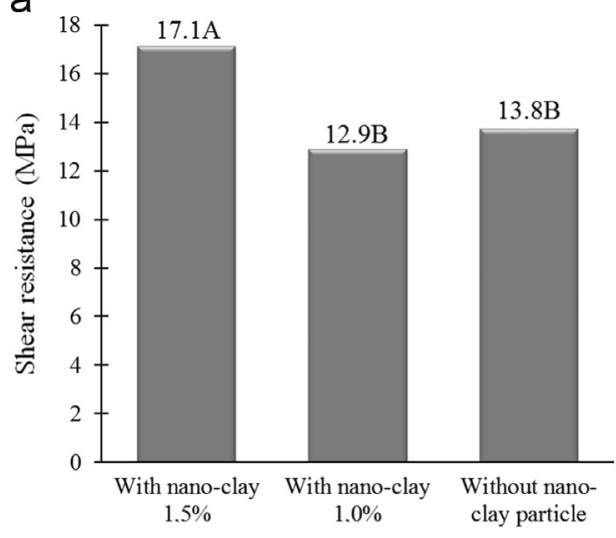

C

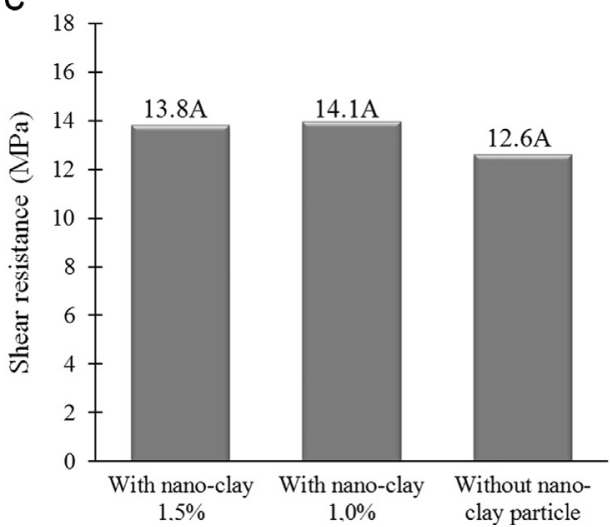

b

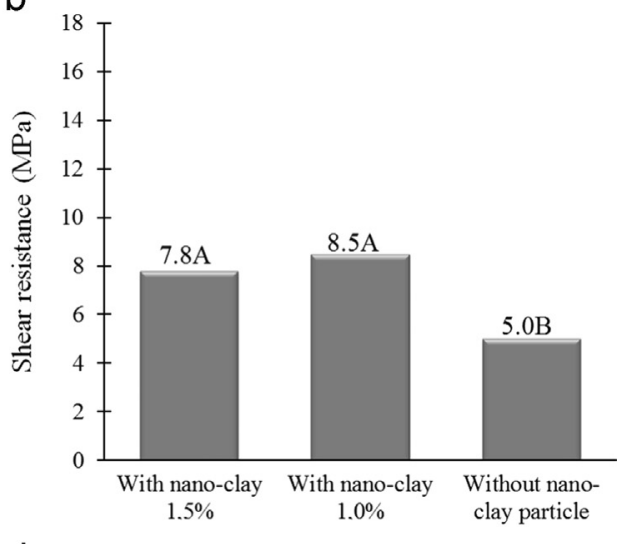

d

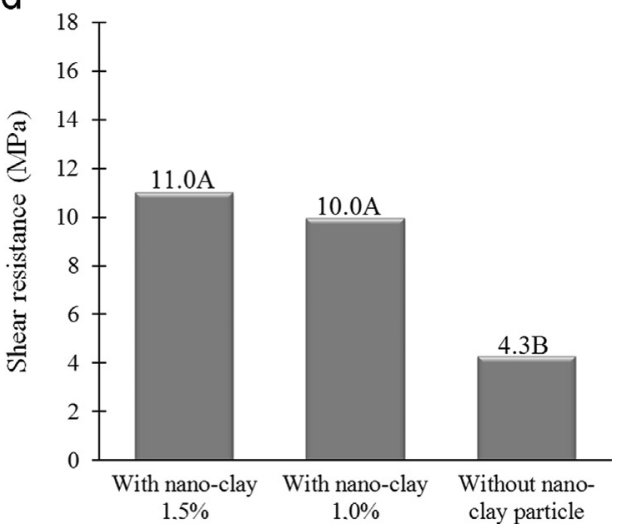

Fig. 5. Resistance of shear strength for dry and wet condition of $C$. guianensis glued with PVA and UF adhesive with and without nano-clay.

Table 4

Moisture content and failure area percentage in shear test of PVAc and UF wood adhesives using different concentrations (weight/weight) of nano-clay.

\begin{tabular}{|c|c|c|c|c|c|}
\hline \multirow[t]{2}{*}{ Parameter } & \multirow[t]{2}{*}{$\begin{array}{l}\text { Nano-clay } \\
\text { concentration (wt\%) }\end{array}$} & \multicolumn{2}{|c|}{$\begin{array}{l}\text { PVAc wood } \\
\text { adhesive }\end{array}$} & \multicolumn{2}{|c|}{$\begin{array}{l}\text { UF wood } \\
\text { adhesive }\end{array}$} \\
\hline & & Dry & Wet & Dry & Wet \\
\hline \multirow[t]{3}{*}{ Moisture content (\%) } & 0.0 & $12.20^{\mathrm{A}}$ & $39.93^{\mathrm{A}}$ & $11.05^{\mathrm{A}}$ & $36.84^{\mathrm{A}}$ \\
\hline & 1.0 & $11.95^{\mathrm{A}}$ & $36.97^{\mathrm{B}}$ & $11.74^{\mathrm{A}}$ & $38.14^{\mathrm{A}}$ \\
\hline & 1.5 & $11.95^{\mathrm{A}}$ & $37.93^{\mathrm{B}}$ & $11.69^{\mathrm{A}}$ & $37.41^{\mathrm{A}}$ \\
\hline \multirow{3}{*}{$\begin{array}{l}\text { Failure area (\%) in } \\
\text { shear test }\end{array}$} & 0.0 & $44.50^{\mathrm{A}}$ & $89.33^{\mathrm{A}}$ & $31.33^{\mathrm{A}}$ & $87.75^{\mathrm{A}}$ \\
\hline & 1.0 & $31.00^{\mathrm{B}}$ & $62.00^{\mathrm{B}}$ & $21.17^{\mathrm{B}}$ & $63.42^{\mathrm{B}}$ \\
\hline & 1.5 & $28.67^{\mathrm{B}}$ & $69.33^{\mathrm{B}}$ & $23.33^{\mathrm{B}}$ & $38.84^{\mathrm{C}}$ \\
\hline
\end{tabular}

wet conditions (Table 4). It is important to note that the samples with nano-clay showed lower water absorption because the moisture content decreased statistically under wet conditions (Table 4).

\section{Discussion}

\subsection{Adhesive characterization}

\subsubsection{Viscosity and color}

Nano-clay addition causes irregularity of the surface (Fig. 2 (b) and (c)). The regularity, or lack thereof, is associated with rugosity values. The rugosity values ( $\mathrm{Ra}$ and $\mathrm{Rq}$ ) are given in Table 1 and they are in agreement with values presented by Kaboorani et al. [2], whose data indicate that low values are attributed to wood adhesives not having nano-clay, the addition of which causes increase of $\mathrm{Ra}$ and $\mathrm{Rq}$ and the higher the amount of added nano-clay, the higher the values of $\mathrm{Ra}$ and $\mathrm{Rq}$. Therefore, the absence of peaks indicated low values of rugosity, and high values of rugosity indicate nano-clay presence. Another relevant aspect, shown by the AFM images, is that peak distribution is slightly uniform, showing no agglomerations of the added nano-clay in the adhesive but adequate dispersion instead $[2,8]$.

\subsubsection{Viscosity and color}

The increase in the viscosity of the adhesive is explained by the fact that exfoliation or even intercalation of clay leads to a strong viscosity increase [26]. Viscosity is highly related to the degree of exfoliation of the clay. Gopakumar et al. [27] have shown that compounds of polypropylene with various types of clay will increase the viscosity of the liquid relative to the increase in exfoliation of the clay. Exfoliation allows for increased adhesion area of the exfoliated clay [26]. It is important to note that, an increase in viscosity was observed from $1 \mathrm{wt} \%$ to $1.5 \mathrm{wt} \%$ concentration in UF adhesive (Fig. 3a), which does not occur with the PVAc adhesive (Fig. 3b). Although the effect of the initial viscosity of pure resin on the final viscosity of resin nano-clay adhesive was not tested in this study, most likely the changes in the viscosity for nano-clay adhesion in modified resin are associated with the initial viscosity of the resin. For example, Zhul and Xanthos [28] found that in resin with higher viscosity, the effect of nano-clay adhesion was greater than resin with lower viscosity. Therefore, the increased amount of nano-clay in PVAc has no effect on viscosity, as occurs with the UF resin.

According to the results for adhesive color (Table 1 ), nano-clay addition, especially in the proportion $1.5 \mathrm{wt} \%$, is likely to change 
color in PVAc and increase luminosity and yellowness. With the UF-adhesive, meanwhile, although a change of tonality occurs (a slightly higher index of yellowness), no color change appears in the adhesives with $1.5 \mathrm{wt} \%$ and $1.0 \mathrm{wt} \%$ nano-clay. The same behavior regarding color change was found by Chaochanchaikul et al. [29] and Awad et al. [30] for PVAc with the different concentrations of nano-clay. They attributed these color changes to high clay concentrations and excellent nano-clay dispersion.

\subsubsection{Thermal stability of the adhesives}

First, adhesives modified with nano-clay demonstrated a different behavior from un-modified adhesives (Fig. 4a-b), most likely influenced by benzalkonium chloride decomposition. The thermogravimetric analysis (TGA) of both types of adhesives prepared with two concentrations of nano-clay (1.0 and $1.5 \mathrm{wt} \%$ ) showed two important inflexions in the mass loss in PVAc adhesive (Fig. 4a), whereas in the case of UF adhesive, only one inflexion was observed (Fig. 4b). These inflexions are related to chemical reactions that occur in each adhesive [7]. However, in the case of the UF adhesive at less than $100{ }^{\circ} \mathrm{C}$, although an inflexion occurred (Fig. 4b), there will be no reaction as this temperature and inflexion correspond to water loss in the urea-formaldehyde resin [31].

The addition of nano-clay in PVAc adhesive produced no significant effects on the decomposition of PVAc as the two common reactions in this polymer are maintained [32-33], which is shown by inflexions in the curves of mass loss (Fig. 4a). Although the decomposition of PVAc is very complex [32-33], note that in the first reaction (at approximately $315^{\circ} \mathrm{C}$ ), the decomposition of acetic acid occurs and in the second reaction (at approximately $425^{\circ} \mathrm{C}$ ), the decomposition of unsaturated polymers is observed.

However, rises in the temperature and the mass remnant in the first reaction (Table 2), together with the higher activation energy (Table 3) observed in PVAc adhesive, indicate that nano-clay increases the thermostability of the PVAc adhesive. These results agree with those found by Peruzzo et al. [6] for PVAc and by Lee and Jang [34], Ollier et al. [21] and Ahamad and Alshehri [35] working on methyl methacrylate, styrene, epoxy precursors, polystyrene, who reported an increase in thermal stability as a result of adding nano-clay to the matrix polymer. Improved thermal stability of nanocomposites is attributed to hindered outdiffusion of the volatile decomposition products (mainly cyclic silicates), as a direct result of the decrease in permeability, usually observed in exfoliated nanocomposite [36]. Valera-Zaragoza et al. [37], working on PPeEP/EVA/organoclay nanocomposites, stated that the retarding process was assigned to the exfoliation and dispersion of the silicate layers that impeded heat diffusion to the macromolecules. In addition, nano-clay maintains greater thermal stability than adhesives (Fig. 4a-b) and therefore this nano-clay produced more thermal stability.

Urea-formaldehyde (UF) resins are thermosetting polymers, prepared by the reaction of two monomers, urea, formaldehyde and water [31]. In the case of nano-clay addition to UF adhesive, normal behavior is observed in this type of resin, a first inflexion at a temperature less than $100{ }^{\circ} \mathrm{C}$, which corresponds to water elimination [31], and a second reaction within a temperature range of $240-265^{\circ} \mathrm{C}$, which corresponds to the degradation of the polymer. In the latter reaction, a series of components is freed, of which the major components are methylene, methylols, dimethylene ethers, methylene methyl ethers, methylene glycols (formaldehyde) and components with carbonyl and triazine groups, among others [38].

As occurred with the PVAc adhesive, adding nano-clay significantly improved the thermal stability of UF adhesive, the initial temperature of the reaction, the temperature of the maximum peak, the mass remnant on the different periods of temperature studied
(Fig. 4e and Table 1) and increased the entropy factor and activation energy in the kinetics of decomposition of the resin (Table 3). These results are consistent with the results obtained by SamaržijaJovanoviĉ et al. [31], Roumeli et al. [39], Hazarika et al. [40], Cai et al. [41] and Doğar et al. [42], which also include studies with the UF adhesive modification with $\mathrm{SiO}_{2}$ nanoparticles or nano-clay. Once again, the increase in thermal stability of the resin was attributed to the dispersion of the silicate layers, which impeded heat diffusion to the macromolecules [42]. However, no significant differences were found in the adhesives with $1.0 \mathrm{wt} \%$ and $1.5 \mathrm{wt} \%$ between the various parameters evaluated in the UF adhesive (Table 2) that can be attributed to saturation or agglomeration of nano-clay [7].

The activation energy of the adhesive without the nano-clay is statistically lower than the energy that occurs in the adhesive with $1.0 \mathrm{wt} \%$ and $1.5 \mathrm{wt} \%$ nano-clay, and increased as a function of nanoclay content (Table 3). This behavior is important because adhesive modified with nano-clay helps to improve the performance of the glue-line in different products fabricated with $C$. guianensis wood, especially in end-uses with high temperature and humidity.

Finally, the results found that no difference in ash content between the adhesive without nano-clay and the adhesives with nano-clay in either of the concentrations can be attributed to lower concentrations of nano-clay utilized, from $1.0 \%$ to $1.5 \%$ (Table 2).

\subsubsection{Bond shear strength}

The results showed that adding nano-clay to PVAc adhesives improves SS both under dry and wet conditions, such as a tropical climate, which tends to cause adhesion problems (Fig. 5a). This result is in agreement with other studies on PVAc-based adhesives $[2,7,9]$ but disagrees in the case of UF adhesives modified with nano-clay [10-13]. The improvement of SS can be explained based on the study conducted by Kaboorani and Riedl [7]. They mentioned that nano-clay can modify the response of a polymer to a load through several mechanisms. Nano-clay particles have an inherently high surface area to volume ratio, leading to a large interfacial area between fillers and matrix. This in turn leads to a suggestion that there is an interaction zone surrounding each filler particle that substantially alters the physical properties relative to the neat polymer matrix, such as higher or lower polymer mobility, entanglement density and altered modulus. In addition, the polymer-clay nanocomposites exhibit extremely strong interfaces with polymers due to the confinement of polymer chains within the galleries of clay platelets. It is possible that the confinement of polymer-clay interactions could affect the local chain dynamics to a certain extent.

Another important aspect regarding the results of humid conditions is that the addition of nano-clay improves the behavior of the percentage of wood failure, particularly with the UF-based resin, but not with the PVAc one (Table 4). Lei et al. [10] presented a hypothesis that first, all montmorillonite nano-clay itself is water repellent and second, the observed reinforcement effect induced by the presence of filler may also be attributed to a percolation phenomenon between the nano-clay particles. Montmorillonite nano-clay particles may be modeled as thin disks. When dispersed inside a continuous medium such as a UF resin matrix, the particles are expected to touch each other, thus forming a connected and infinite cluster even at low concentrations. Thus, the water resistance increased in the UF resin, but most likely the affinity of PVAc resin with water did not permit adequate resistance.

\section{Conclusion}

The montmorillonite type nano-clay modified with benzalkonium chloride $\left(\mathrm{C}_{6} \mathrm{H}_{5} \mathrm{CH}_{2} \mathrm{~N}\left(\mathrm{CH}_{3}\right)\right.$ 2RCl$)$ and added to polyvinyl 
acetate (PVAc) and urea-formaldehyde (UF) improved the thermogravimetric properties of these adhesives, increased starting temperature, increased maximum peak temperature, increased mass remnant in the different temperature periods studied of the reactions present in the adhesives and increased entropy factor and activation energy of the kinetics of decomposition of the resin. In addition, PVAc and UF adhesives with the modified nano-clay affected other physical features, slightly increasing the viscosity of the resin and the brightness and the yellowness of the adhesives, especially in the proportion of $1.5 \%$.

Nano-clay added in PVAc and UF adhesives improved shear strength of the glue line (SS) and the percentage of wood failure (PWF). The highest values of SS were obtained when nano-clay was added in $1.5 \mathrm{wt} \%$ in PVAc adhesive under dry conditions. SS was not affected by nano-clay addition in UF adhesive under dry conditions. However, under wet conditions, both 1.0 and $1.5 \mathrm{wt} \%$ of nano-clay into adhesive increased SS in the two adhesives. The addition of nano-clay in the two proportions increased PWF at $15 \%$ and between $20 \%$ and $30 \%$ under both dry and wet conditions, respectively for PVAc adhesive. In the UF adhesive, PWF increased $10 \%$ under dry conditions and $25-50 \%$ under wet conditions.

\section{Acknowledgments}

The authors wish to thank the Vicerrectoría de Investigación y Extensión at the Instituto Tecnológico de Costa Rica (ITCR) for financial support for the study.

\section{References}

[1] Stoeckel F, Johannes K, Wolfgang G. Mechanical properties of adhesives for bonding wood-a review. Int J Adhes Adhes 2013;45:32-41.

[2] Kaboorani A, Riedl B, Blanchet P. Ultrasonication technique: a method for dispersing nano-clay in wood adhesives. J Nanomater 2013;3:1-9.

[3] Zhao LF, Liu Y, Xu ZD, Zhang YZ, Zhao F, Zhang SB. State of research and trends in development of wood adhesives. For Stud China 2011;13:321-6.

[4] Roussak OV, Gesser HD. Adhesives and adhesion. Applied Chemistry. US: Springer; 2013. p. 219-32.

[5] Mohan P. A critical review: the modification, properties, and applications of epoxy resins. Polym-Plast Technol Eng 2013;52.2:107-25.

[6] Peruzzo PJ, Bonnefond A, Reyes Y, Fernández M, Fare J, Ronne E, et al. Beneficial in-situ incorporation of nano-clay to waterborne PVAc/PVOH dispersion adhesives for wood applications. Int $J$ Adhes Adhes 2014:48:295-302.

[7] Kaboorani A, Riedl B. Effects of adding nano-clay on performance of polyvinyl acetate (PVA) as a wood adhesive. Compos Part A: Appl Sci Manuf 2011;42 (8):1031-9.

[8] Kaboorani A, Riedl B, Blanchet P, Fellin M, Hosseinaei O, Wang S. Nanocrystalline cellulose (NCC): a renewable nano-material for polyvinyl acetate (PVA) adhesive. Eur Polym J 2012;48:1829-37.

[9] Pique TM, Pérez C], Alvarez VA, Vázquez A. Water soluble nanocomposite films based on poly (vinyl alcohol) and chemically modified montmorillonites. J Compos Mater 2014;48:545-53.

[10] Lei H, Du G, Pizzi A, Celzard A. Influence of nano-clay on urea-formaldehyde resins for wood adhesives and its model. J Appl Polym Sci 2008; 109(4):2442-51.

[11] Pirayesh H, Khanjanzadeh H, Salari A. Effect of using walnut/almond shells on the physical, mechanical properties and formaldehyde emission of particleboard. Compos Part B: Eng 2013;45(1):858-63.

[12] Xian D, Semple KE, Haghdan S, Smith GD. Properties and wood bonding capacity of nano-clay-modified urea and melamine formaldehyde resins. Wood Fiber Sci 2013;45(4):383-95.

[13] Ates E, Uyanik N, Kizilcan N. Preparation of urea formaldehyde resin/layered silicate nanocomposites. Pigment Resin Technol 2013;42:283-7.
[14] Bourreau D, Aimene Y, Beauchêne J, Thibaut B. Feasibility of glued laminated timber beams with tropical hardwoods. Eur J Wood Prod 2013;71(5):653-62.

[15] Gérard J. Specific features of tropical hardwoods bondability: adding values to secondary wood species and multi-species gluing (In French). Ann Génie Civil Bois Collage Struct 1999;1:15-30.

[16] Sinha Ray S, Okamoto M. Polymer/layered silicate nanocomposites: a review from preparation to processing. Prog Polym Sci 2003;28(11):1539-641.

[17] Diener BJ, Saklad H. Portico SA. J Bus Res 1997;38(1):89-96.

[18] Chahud E, Rocco FA, Rosi RR. O uso de espécies nativas comercializadas em Belo Horizonte na composição de madeira laminada colada. Construindo 2009;1:42-9.

[19] ASTM. (2013). D905-08.Standard test method for strength properties of adhesive bonds in shear by compression loading. Annual book of ASTM standards, 2013, vol.11 (06), 5 p.

[20] Ollier R, Vázquez A, Alvarez V. Biodegradable nanocomposites based on modified bentonite and polycaprolactone. Adv Nanotech 2011;1:1-10.

[21] Ollier R, Rodriguez E, Alvarez V. Unsaturated polyester/bentonite nanocomposites: influence of clay modification on final performance. Compos Part A: Appl Sci Manuf 2013;48:137-43.

[22] Hunterlab. In: Richard S, Hunter R, Richard W Harold, editors. The Measurement of Appearance. New York: Published by John Wiley \& Sons, Inc; 1995.

[23] ASTM. Standard practice for calculation of color tolerances and color differences from instrumentally measured color coordinates (D 2244-02). Pennsylvania: Book of standards. 2013, vol. 11(06).

[24] Vyazovkin S, Sbirrazzuoli N. Isoconversional kinetic analysis of thermally stimulated processes in polymers. Macromol Rapid Commun 2006;27(18): 1515-1532.

[25] ASTM. D5266-13. Standard practice for estimating the percentage of wood failure in adhesive bonded joints. Annual book of ASTM standards 2013b, vol. 11(06).

[26] Landry V, Bernard R, Blanchet P. Nanoclay dispersion effects on UV coatings curing. Prog Org Coat 2008;62:400-8.

[27] Gopakumar TG, Lee JA, Kontopoulou M, Parent JS. Influence of clay exfoliation on the physical properties of montmorillonite/polyethylene composites. Polymer 2002;43:5483-91.

[28] Zhu1 L, Xanthos M. Effects of process conditions and mixing protocols on structure of extruded polypropylene nanocomposites. J Appl Polym Sci 2004;93(4):1891-9.

[29] Chaochanchaikul K, Rosarpitak V, Sombatsompop N. Structural and therma stabilization of PVC and wood/PVC composites by metal stearates and organotin. BioResources 2011:6(3):3115-31.

[30] Awad WH, Beyer G, Benderly D, Ijdo WL, Songtipya P, Jimenez-Gasco MDM et al. Material properties of nano-clay PVC composites. Polymer 2009; 50(8):1857-67.

[31] Samaržija-Jovanović S, Jovanović V, Konstantinović S, Marković G, MarinovićCincović M. Thermal behaviour of modified urea-formaldehyde resins. J Ther Anal Calorim 2011;104(3):1159-66.

[32] Blazevska-Gilev J, Spaseska D. Thermal degradation of PVAc. J Univ Chem Technol Metall 2005;40(4):287-90.

[33] McNeill IC, Memetea L, Cole WJ. A study of the products of PVC thermal degradation. Polym Degrad Stab 2005;49(1):181-91.

[34] Lee DC, Jang LW. Characterization of epoxy-clay hybrid composite prepared by emulsion polymerization. J Appl Polym Sci 1998;68(12):1997-2005.

[35] Ahamad T, Alshehri SM. Thermal degradation and evolved gas analysis: a polymeric blend of urea formaldehyde (UF) and epoxy (DGEBA) resin. Arab J Chem 2014;7(6):1140-7.

[36] Burnside SD, Giannelis. EP. Synthesis and properties of new poly (dimethylsiloxane) nanocomposites. Chem Mater 1995;7(9):1597-600.

[37] Valera-Zaragoza M, Ramírez-Vargas E, Medellín-Rodríguez FJ, Huerta-Martínez BM. Thermal stability and flammability properties of heterophasic PPeEP/EVA/ organoclay nanocomposites. Polym Degrad Stab 2006;91(6):1319-25.

[38] Siimer K, Kaljuvee T, Christjanson P. Thermal behaviour of urea-formaldehyde resins during curing. J Ther Anal Calorim 2003;72(2):607-17.

[39] Roumeli E, Papadopoulou E, Pavlidou E, Vourlias G, Bikiaris D, Paraskevopoulos KM, et al. Synthesis, characterization and thermal analysis of ureaformaldehyde/nanoSiO 2 resins. Thermochim Acta 2012;527:33-9.

[40] Hazarika A, Mandal M, Maji TK. Dynamic mechanical analysis, biodegradability and thermal stability of wood polymer nanocomposites. Compos Part B: Eng 2014:60:568-76.

[41] Cai X, Riedl B, Wan H, Zhang SY, Wang XM. A study on the curing and viscoelastic characteristics of melamine-urea-formaldehyde resin in the presence of aluminium silicate nano-clays. Compos Part A: Appl Sci Manuf 2010;41(5):604-11.

[42] Doğar Ç, Gürses A, Karaca S, Köktepe S, Mindivan F, Güneş K. Investigation of thermal properties of PUF/clay nanocomposites. Appl Surf Sci 2013. 